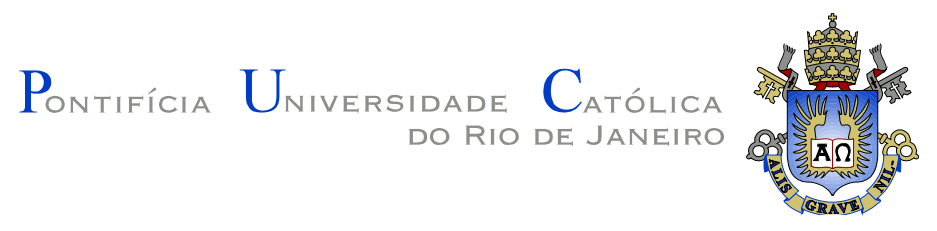

Raquel Alves Cabral Silva

\title{
Análise Teórica-Experimental de Ligação Viga-Pilar Semirrígida Mista com Conectores Tipo "Perfobond" nas Vigas
}

Dissertação de Mestrado

Dissertação apresentada como requisito parcial para obtenção do grau de Mestre pelo Programa de Pós-Graduação em Engenharia Civil do Departamento de Engenharia Civil da PUC-Rio.

Orientador: Sebastião Arthur Lopes de Andrade 


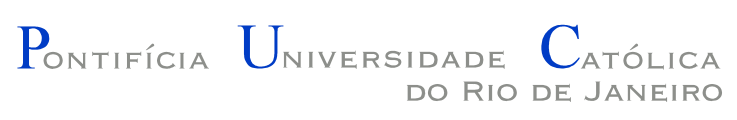

Raquel Alves Cabral Silva

\section{Análise Teórica-Experimental de Ligação Viga-Pilar Semirrígida Mista com Conectores Tipo "Perfobond" nas Vigas}

Dissertação apresentada como requisito parcial para obtenção do grau de Mestre pelo Programa de PósGraduação em Engenharia Civil do Departamento de Engenharia Civil do Centro Técnico Científico da PUCRio. Aprovada pela Comissão Examinadora abaixo assinada.

Prof. Sebastião Arthur Lopes de Andrade Orientador

Departamento de Engenharia Civil - PUC-Rio

Prof. Raul Rosas e Silva

Departamento de Engenharia Civil - PUC-Rio

Prof. Luciano R. Ornelas de Lima Universidade do Estado do Rio de Janeiro

Prof. Pedro Colmar G. da Silva Vellasco Universidade do Estado do Rio de Janeiro

Prof. José Eugenio Leal Coordenador Setorial do Centro Técnico Científico - PUC-Rio

Rio de Janeiro, 03 de julho de 2015. 
Todos os direitos reservados. É proibida a reprodução total ou parcial do trabalho sem autorização da universidade, do autor e do orientador.

\section{Raquel Alves Cabral Silva}

Graduou-se em Engenharia Civil pela Universidade Federal de Sergipe - UFS. Na PUC-Rio desenvolveu pesquisas na área de estruturas, atuando na linha de ligações semirrígidas.

Ficha Catalográfica

Silva, Raquel Alves Cabral

Análise teórica-experimental de ligação viga-pilar semirrígida mista com conectores tipo "perfobond” nas vigas / Raquel Alves Cabral Silva; orientador: Sebastião Arthur Lopes de Andrade. - 2015.

165 f. : il. (color.) ; $30 \mathrm{~cm}$

Dissertação (mestrado)-Pontifícia Universidade Católica do Rio de Janeiro, Departamento de Engenharia Civil, 2015.

Inclui bibliografia

1. Engenharia civil - Teses. 2. Ligações mistas 3. Ligações semirrígidas. 4. Ligações viga-pilar. 5. Análise experimental. 6. Ligações com cantoneiras. I. Andrade, Sebastião Arthur Lopes de. II. Pontifícia Universidade Católica do Rio de Janeiro. Departamento de Engenharia Civil. III. Título.

CDD: 624 


\section{Agradecimentos}

A Deus, primeiramente, pela força nos momentos difíceis.

Ao meu orientador, Sebastião Andrade, por toda a ajuda, confiança e amizade na realização deste trabalho. Por me passar tantos conhecimentos novos durante este tempo, possibilitando um grande amadurecimento profissional.

Aos meus pais por serem tão presentes, por sempre me apoiarem e pela compreensão nos momentos de ausência.

As minhas irmãs, Juliane e Luiza, por serem companheiras mesmo de longe.

A Matheus, pelo carinho, por me apoiar e compreender o tempo em que estive distante.

Aos funcionários do Laboratório de Estruturas da PUC-Rio, Euclides, Rogério, Alex, José Nilson, Carlos, por toda a ajuda prestada e pelo bom convívio no período de realização dos ensaios.

A César por ser um companheiro na realização deste trabalho, auxiliando nas tarefas de laboratório e nos momentos difíceis do curso.

A todos os professores do Departamento de Engenharia Civil da PUC-Rio e da UFS que de alguma forma contribuíram com vários conhecimentos para a minha formação.

Aos colegas de curso pelos grupos de estudo, pela boa convivência e pela amizade durante os dois anos de curso.

A CAPES pelo auxílio financeiro no desenvolvimento deste trabalho.

A Metalfenas por fornecer os perfis metálicos para realização dos ensaios.

A PERIPLÁSTICOS por fornecerem os espaçadores utilizados nos ensaios 


\section{Resumo}

Silva, Raquel Alves Cabral; Andrade, Sebastião Arthur Lopes de (Orientador). Análise teórica-experimental de uma ligação viga-pilar mista semirrígida com conectores tipo "Perfobond" nas vigas. Rio de Janeiro, 2015. 165p. Dissertação de Mestrado - Departamento de Engenharia Civil, Pontifícia Universidade Católica do Rio de Janeiro.

Nos projetos de engenharia é comum desconsiderar-se o comportamento semirrígido das ligações, ou seja, as ligações são assumidas com as condições ideais de rigidez. A primeira condição ideal é aquela na qual há transferência total de momento fletor, assumindo-se que não existe rotação relativa entre os elementos ligados, estas ligações são as chamadas rígidas. Na segunda opção, a transferência de momento fletor é desconsiderada e a ligação é definida como rotulada ou simples. Entretanto, sabe-se que a maioria das ligações comporta-se como semirrígida e o problema é que ao se fazer essas simplificações em projeto, dois aspectos podem ser comprometidos: segurança estrutural e custo do projeto. Neste trabalho, uma ligação semirrígida mista é proposta e estudada com o objetivo de obter-se as suas características principais e necessárias para utilizá-la em projeto: curva momento-rotação, rigidez de serviço e momento fletor resistente. Com a ligação mista proposta, busca-se uma nova maneira de transferência de forças na região de momento negativo em uma viga semicontínua. Adotou-se para a transferência dos esforços, entre a laje de concreto e a viga de aço, conectores de cisalhamento do tipo "Perfobond Rib". Este conector foi inicialmente utilizado em pontes e depois alguns estudos o viabilizaram para o uso em edificações. Para atingir os objetivos do trabalho, foram realizados dois ensaios em escala real das ligações propostas. Os testes experimentais foram feitos em modelos cruciformes invertidos e realizados no laboratório de estruturas e materiais da PUC-Rio. Os resultados experimentais foram comparados com dois modelos analíticos: o método proposto por Leon et al. em 1996 e o método presente no Anexo R da NBR 8800:2008.

\section{Palavras-chave}

Ligações mistas; ligações semirrígidas; ligações viga-pilar; análise experimental; ligações com cantoneiras. 


\section{Abstract}

Silva, Raquel Alves Cabral; Andrade, Sebastião Arthur Lopes de (Advisor). Theoretical and experimental analysis of a composite semi-rigid beamto-column joint using Perfobond shear connectors. Rio de Janeiro, 2015. 165p. MSc. Dissertation - Departamento de Engenharia Civil, Pontifícia Universidade Católica do Rio de Janeiro.

In engineering design it is common to disregard the semi-rigid behavior of connections, i.e., connections are assumed to have the ideal conditions of rigidity. The first ideal condition is the one in which there is full transfer of bending moment, assuming that there is no relative rotation between the connected elements, this connection is defined rigid. In the second option, the transfer of bending moment is disregarded and the connection is defined simple. However, it is known that most connections have a semi-rigid behavior and the problem is that when making these simplifications in design, two aspects can be compromised: structural safety and project cost. In this work, a composite semi-rigid connection is studied in order to obtain its main and necessary features to use it in design: moment-rotation curve, service rigidity and bending moment capacity. With the proposed composite connection, a new way to transfer forces in the negative moment region on a semicontinous beam. Shear connectors like the "Perfobond $R i b$ " were adopted for the transfer of efforts between the concrete slab and the steel beam. This connector was first used on bridges and since then some studies have made possible its use in buildings, showing its advantages over the more usual connectors. To achieve this work's objectives, two real scale tests of the proposed connections were conducted. Experimental tests were done in inverted cruciform models and carried out in the laboratory of structures and materials at PUC-Rio. Information on these tests was obtained, such as displacements, strains, and cracking of the slab. The experimental results were compared to two analytical models: the method proposed by Leon et al. in 1996 and the present method in Annex R of NBR 8800: 2008.

\section{Keywords}

Composite connections; semi-rigid connections; beam to column connections; experimental analysis; web and seat angle connections. 


\section{Sumário}

1 Introdução $\quad 24$

1.1. Considerações iniciais $\quad 24$

1.2. Objetivos 25

1.3. Revisão Bibliográfica 26

1.4. Estrutura do documento 31

2 Ligações mistas viga-pilar 33

2.1. Considerações gerais 33

2.2. Classificação das construções segundo o AISC (American Institute of Steel Construction) 35

2.3. Classificação das Ligações 36

2.3.1. Classificação das ligações segundo o AISC 36

2.3.2. Classificação das ligações segundo o Eurocode 39

2.3.3. Classificação das ligações segundo a NBR 8800:2008 41

2.4. Ligações semirrígidas mistas 41

2.4.1. Ligações semirrígidas mistas do Tipo I 43

2.4.2. Largura efetiva da laje para regiões de momento negativo (NBR 8800:2008) 44

2.4.3. Conectores de cisalhamento 45

2.4.3.1. Conectores de cisalhamento do tipo "Perfobond rib" 45

2.5. Curva momento-rotação das ligações 46

2.6. Método de análise proposto pelo AISC: "Steel Design Guide Series: $8 "$

2.6.1. Considerações iniciais 49

2.6.2. Comportamento das ligações 49

2.6.3. Condições para escolha inicial da ligação 51

2.6.4. Análise 52

2.6.4.1. Análise "Beam Line" 52

2.6.4.2. Momento resistente para cargas gravitacionais 53 
2.6.5. Considerações de projeto

2.6.5.1. Deslocamentos de vigas com PR-CC 54

2.6.5.2. Rigidez da viga 55

2.6.6. Detalhamento da armadura 56

2.7. Método de análise proposto pela ABNT NBR 8800: 2008

2.7.1. Ligações mistas $\quad 56$

2.7.2. Momento fletor resistente de cálculo em regiões de momento negativo para vigas mistas $\quad 59$

2.7.3. Capacidade de rotação necessária 60

2.8. Método de análise proposto pelo Eurocode 62

3 Procedimento para projeto de ligações do tipo PR-CC 63

3.1. Considerações Iniciais 63

3.2. Dados de projeto 66

3.2.1. Escolha inicial do perfil de aço da viga 66

3.2.2. Características da laje 67

3.2.3. Cargas previstas 68

3.2.4. Solicitações de projeto 69

3.2.4.1. Momento fletor antes da cura $\left(\mathrm{M}_{\mathrm{a}}\right)$

3.2.4.2. Momento fletor depois da cura $\left(M_{d}\right)$

3.3. Verificações de resistência e rigidez 69

3.3.1. Escolha inicial do perfil 69

3.3.2. Deslocamento inicial 70

3.3.3. Momento resistente da viga mista 70

3.3.3.1. Necessidade de PR-CC quanto à resistência 72

3.3.4. Condições de serviço (rigidez) 73

3.3.4.1. Momento de inércia para o mínimo de interação ( (LB,PNA7) 73

3.3.4.2. Momento de inércia para viga biapoiada $\left(\mathrm{L}_{\mathrm{LB}, \mathrm{sS}}\right)$

3.3.4.3. Momento de inércia para a viga parcialmente restriginda $\left(\mathrm{I}_{\mathrm{LB}, \mathrm{PR}}\right) 74$

3.3.4.4. Necessidade de PR-CC quanto à rigidez 75

3.4. Projeto de PR-CC para cargas gravitacionais 75

3.4.1. Resistência última 75

3.4.2. Rigidez 76 
3.5. Determinação da ligação metálica, parafusos e armadura transversal

3.5.1. Cantoneira de assento 78

3.5.1.1. Parafusos 79

3.5.2. Dupla cantoneira de alma 79

3.5.3. Armadura transversal 80

3.5.3.1. Distribuição das barras de aço 80

4 Descrição do Programa Experimental 82

4.1. Considerações Gerais 82

4.2. Parâmetros de Projeto 82

4.3. Características Geométricas dos Modelos 84

4.4. Fabricação das peças $\quad 89$

4.5. Controle Dimensional das Peças 91

4.5.1. Especificação das Dimensões das Peças 91

4.5.2. Levantamento da geometria dos elementos utilizados no Ensaio 192 4.5.3. Levantamento da geometria dos elementos utilizados no Ensaio 293 4.6. Propriedades dos materiais 94

4.6.1. Concreto 94

4.6.2. Aço 96

4.7. Montagem dos ensaios 96

4.8. Instrumentação 101

4.8.1. Primeiro ensaio 101

4.8.1.1. Deformações 101

4.8.1.2. Deslocamentos 104

4.8.2. Segundo ensaio 104

4.9. Procedimento de Ensaio 105

4.9.1. Primeiro ensaio 105

$\begin{array}{ll}\text { 4.9.2. Segundo ensaio } & 107\end{array}$

5 Resultados experimentais $\quad 110$

5.1. Introdução 110

5.2. Resultados obtidos no primeiro ensaio 110 
5.2.1. Deslocamentos 111

5.2.2. Tensões 113

5.2.2.1. Armadura 113

5.2.2.2. Vigas e cantoneiras 115

$\begin{array}{ll}\text { 5.2.3. Fissuras na laje } & 118\end{array}$

5.2.4. Momento-rotação 119

5.3. Resultados obtidos no segundo ensaio 123

5.3.1. Deslocamentos 123

5.3.2. Tensões 125

5.3.2.1. Armadura 125

$\begin{array}{ll}\text { 5.3.2.2. Vigas e cantoneiras } & 127\end{array}$

$\begin{array}{ll}\text { 5.3.3. Tensões } & 129\end{array}$

5.3.4. Fissuras na laje 129

5.3.5. Momento-rotação 131

6 Previsões teóricas 133

6.1. Cálculo segundo procedimento de Leon et al. (1996) 133

6.1.1. Momento resistente da ligação 133

6.1.2. Rigidez de serviço 134

6.1.3. Curva momento-rotação 134

6.2. Cálculo segundo o Anexo R da NBR 8800:2008 136

6.2.1. Barras de armadura tracionadas 136

6.2.1.1. Rigidez inicial 136

6.2.1.2. Força resistente de cálculo 136

6.2.1.3. Capacidade de deformação 136

6.2.2. Conectores de cisalhamento 137

$\begin{array}{ll}\text { 6.2.2.1. Rigidez inicial } & 137\end{array}$

6.2.2.2. Força resistente de cálculo 138

6.2.2.3. Capacidade de deformação 139

6.2.3. Ligação da mesa inferior da viga apoiada 139

6.2.3.1. Rigidez inicial 139

6.2.3.2. Força resistente de cálculo 140

$\begin{array}{ll}\text { 6.2.3.3. Capacidade de deformação } & 141\end{array}$ 
$\begin{array}{ll}\text { 6.2.4. Ligação de alma da viga apoiada } & 141\end{array}$

$\begin{array}{ll}\text { 6.2.5. Rigidez inicial da ligação } & 142\end{array}$

6.2.6. Momento resistente da ligação 142

6.2.7. Capacidade de rotação 143

6.2.8. Curva momento-rotação (bilinear) 143

6.2.9. Resistência da viga mista a momento fletor negativo 144

$\begin{array}{ll}\text { 6.3. Modelo no Ftool } & 144\end{array}$

7 Análise dos resultados $\quad 146$

7.1. Considerações iniciais 146

$\begin{array}{ll}\text { 7.2. Discussão dos resultados } & 146\end{array}$

8 Considerações finais 156

$\begin{array}{ll}\text { 8.1. Conclusões } & 157\end{array}$

đ $\quad$ 8.2. Sugestões para trabalhos futuros 159

$\begin{array}{lr}\text { Referências Bibliográficas } & 161\end{array}$ 


\section{Lista de Figuras}

Figura 1.1 - Gráfico comparativo entre uma ligação mista e uma somente metálica, Leon e Ammerman (1987)

Figura 2.1 - gráficos de momento fletor para ligações flexíveis, rígidas e semirrígidas. 35

Figura 2.2 - Modelos cruciformes para análise experimental de ligações intermediárias. 35

Figura 2.3 - Limites de classificação representados na curva momentorotação, adaptada de Leon (1999).

Figura 2.4 - Definição da capacidade de rotação, $\theta$ u, da ligação segundo

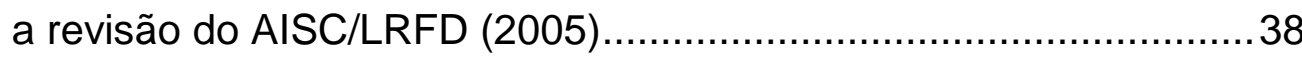

Figura 2.5 - Classificação do Eurocode segundo à rigidez ......................40

Figura 2.6 - Ligações semirrígidas dos tipos I, II, III e IV ...........................42

Figura 2.7 - Ligação semirrígida mista proposta .................................... 43

Figura 2.8 - Distância simplificada entre os pontos de momento nulo em uma viga contínua e semicontínua, NBR 8800: 2008 ....................... 45

Figura 2.9 - Representação do conector tipo "Perfobond Rib" ................46

Figura 2.10 - Tipos de curvas momento-rotação, CHEN et. al 2011 ........47

Figura 2.11 - Definição das rigidezes de uma ligação, adaptada de Leon et al. (1996). 48

Figura 2.12 - Fases da curva M- $\theta$ de uma ligação mista, adaptada de

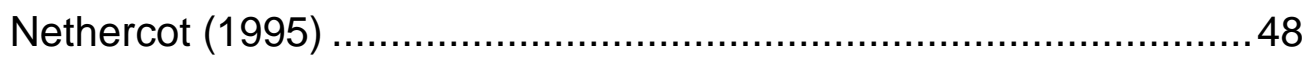

Figura 2.13 - Ligação proposta por Leon et al, 1996 ...............................50

Figura 2.14 - Forças resistentes na ligação.............................................51

Figura 2.15 - Classificação quanto à rigidez, AISC 2010 ........................51

Figura 2.16 - "Beam Line", adaptada de Leon et al., 1996 .......................53

Figura 2.17 - Componentes que contribuem para a rigidez sob momento

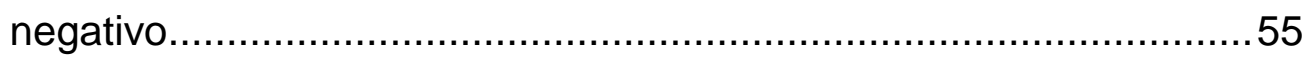

Figura 2.18 - Recomendações para o detalhamento da armadura,

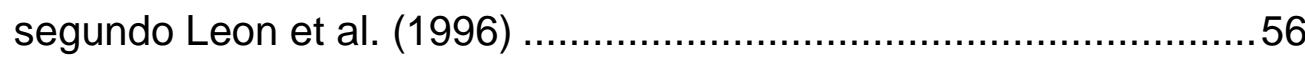

Figura 2.19 - Ligação mista proposta pela NBR 8800:2008 …..................57 
Figura 2.20 - Posição da LNP para que a contribuição da ligação de alma seja desconsiderada, NBR 8800:2008 59

Figura 2.21 - Distribuição de tensões para momento fletor negativo

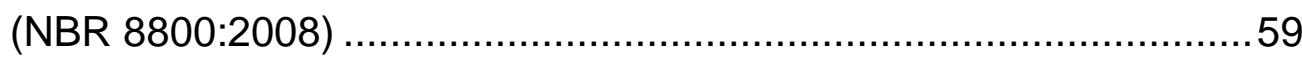

Figura 3.1 - Planta baixa de estudo...........................................64

Figura 3.2 - Viga mista escolhida para o projeto .................................64

Figura 3.3 - Detalhes da Steel Deck..............................................64

Figura 3.4 - Passo a passo de projeto utilizando-se o procedimento descrito no Guide 8 do AISC ....................................................65

Figura 3.5 - Carga "ideal" para uma viga de comprimento igual a 10 metros 67

Figura 3.6 - Detalhes da laje tipo Steel Deck ..................................68

Figura 3.7 - Representação das dimensões na viga mista.....................70

Figura 3.8 - Representação da seção resistente da viga mista em

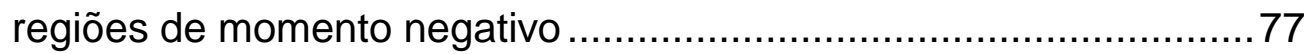

Figura 3.9 - Detalhe das dimensões da cantoneira de assento...............79

Figura 3.10 - Detalhe das dimensões da cantoneira de alma .................80

Figura 3.11 - Detalhamento da armadura ...................................... 81

Figura 4.1 - Planta baixa do pavimento estrutural ..............................83

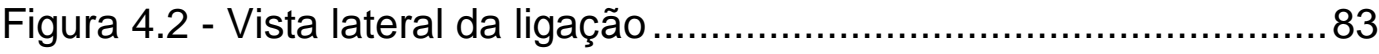

Figura 4.3 - Configuração de teste ............................................... 84

Figura 4.4- Detalhes do parafuso utilizado ........................................... 85

Figura 4.5 - Detalhes da vista lateral da ligação...................................85

Figura 4.6 - CORTE A-A - Detalhes da vista frontal da ligação ...............86

Figura 4.7 - Detalhes do "perfobond" utilizado .................................. 86

Figura 4.8 - Nomenclatura utilizada para os "perfobonds" .....................87

Figura 4.9 - Detalhes da armação principal.......................................... 87

Figura 4.10 - Projeto da armação principal e secundária .........................88

Figura 4.11 - Projeto de fabricação das cantoneiras de assento...............89

Figura 4.12- Projeto de fabricação das cantoneiras de alma ..................89

Figura 4.13 - Projeto de fabricação das vigas .....................................90

Figura 4.14 - Projeto de fabricação dos pilares .................................91

Figura 4.15 - Padronização das dimensões dos elementos da ligação: viga, cantoneira de assento e cantoneira de alma, respectivamente 92 
Figura 4.16 - Detalhe da máquina utilizada para o ensaio de

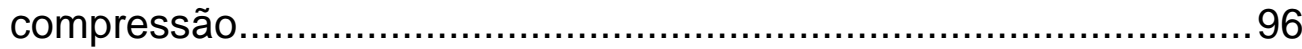

Figura 4.17 - Detalhe da ligação metálica .......................................98

Figura 4.18 - Detalhe da fôrma de fechamento das lajes .....................98

Figura 4.19 - Solda dos "perfobonds" ......................................... 98

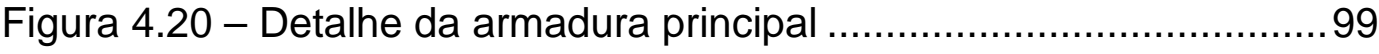

Figura 4.21 - Detalhe da armação completa .......................................99

Figura 4.22 - Detalhe da armadura no "Perfobond"................................99

Figura 4.23 - Concretagem........................................................... 100

Figura 4.24 - Transporte e inversão do modelo experimental, respectivamente ................................................................ 100

Figura 4.25 - Instrumentação: "strain gauges" nos vergalhões .............. 101

Figura 4.26 - Instrumentação: posição dos "strain gauges" nos

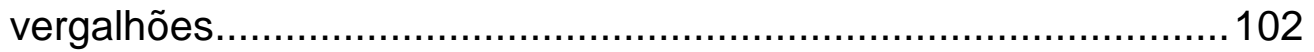

Figura 4.27 - Instrumentação: representação das rosetas e extensômetros nas cantoneiras de alma, Ensaio 1...................... 102

Figura 4.28 - Instrumentação: detalhe da sequência para colagem das rosetas na cantoneira de alma ........................................... 103

Figura 4.29 - Instrumentação pronta das cantoneiras de alma ............. 103

Figura 4.30 - Instrumentação: representação dos extensômetros nas

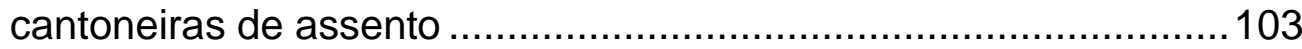

Figura 4.31 - Instrumentação pronta das cantoneiras de assento.......... 103 Figura 4.32 - Instrumentação: representação dos extensômetros nas vigas

Figura 4.33 - Instrumentação: representação do posicionamento dos transdutores de deslocamento 104

Figura 4.34 - Instrumentação: representação das rosetas e extensômetros nas cantoneiras de alma, Ensaio 2 105

Figura 4.35 - Representação 3D do sistema de aplicação de carga utilizado

Figura 4.36 - Esquema de ensaio utilizado para o protótipo 1 107

Figura 4.37 - Esquema do ensaio utilizado para o último carregamento do Ensaio 1 e todos os estágios do Ensaio 2 
Figura 4.38 - Detalhe do sistema de aplicação de carga e da aquisição de dados, Ensaio 2

Figura 4.39 - Detalhe do atuador fixado na laje de reação, Ensaio 2.... 109

Figura 5.1 - Gráfico "carga aplicada versus deslocamento", para o último estágio de carregamento, dos transdutores pertencentes ao Ensaio 1

Figura 5.2 - Gráfico "carga aplicada versus deslocamento" do transdutor 4, referente ao Ensaio 1

Figura 5.3 - Deslocamento do modelo experimental para algumas cargas do Ensaio 1

Figura 5.4 - Gráfico "carga aplicada x tensão" das barras de aço do

Ensaio 1

Figura 5.5 - Gráficos "carga aplicada x tensão" para as barras de aço.. 115

Figura 5.6 - Gráfico "carga aplicada versus tensão" das vigas do

Ensaio 1

Figura 5.7 - Gráfico "carga aplicada versus tensão" das cantoneiras de assento do Ensaio 1

Figura 5.8 - Gráfico "carga aplicada versus tensão" das cantoneiras de alma do Ensaio 1 - extensômetros horizontais

Figura 5.9 - Distribuição de tensões para a carga última nas vigas 1

e 2 do Ensaio 1

Figura 5.10 - Gráfico "altura da Viga 2 versus tensão" para alguns estágios de carregamento do Ensaio 1

Figura 5.11 - Representação das fissuras na laje do Ensaio 1 118

Figura 5.12 - Detalhe da primeira fissura observada $(40 \mathrm{kN})$ e da fissura

na linha do pilar $(60 \mathrm{kN})$

Figura 5.13 - Na foto superior o aparecimento da fissura na linha do

Pe01; na foto inferior a mesma região ao término do Ensaio 1.

Figura 5.14 - Detalhe das fissuras que limitaram o Ensaio 1

Figura 5.15 - Representação da deformada da viga

Figura 5.16 - Representação do cálculo do momento na ligação. 120

Figura 5.17 - Curvas M- $\theta$ para os lados direito e esquerdo da ligação -

Ensaio 1 
Figura 5.18 - Curvas $M-\theta$ para alguns estágios de carregamento do

Ensaio 1, lado direito.

Figura 5.19 - Detalhe do modelo ao final do Ensaio 1 ....................... 122

Figura 5.20 - Detalhe da rotação da ligação ao final do Ensaio 1 ..........123

Figura 5.21 - Gráfico "carga aplicada versus deslocamento" dos

transdutores pertencentes ao Ensaio 2................................. 124

Figura 5.22 - Deslocamento do modelo experimental para alguns

estágios de carga do Ensaio 2

Figura 5.23 - Gráfico "carga aplicada x tensão" das barras de aço do

Ensaio 2

Figura 5.24 - Gráficos "carga aplicada x tensão" para as barras de aço - Ensaio 2

Figura 5.25 - Gráfico "carga aplicada x tensão" das vigas do Ensaio 2.127

Figura 5.26 - Gráfico "carga aplicada versus tensão" das cantoneiras de assento do Ensaio 2

Figura 5.27 - Gráfico "carga aplicada versus tensão" das cantoneiras de alma do Ensaio 2 - extensômetros horizontais 128

Figura 5.28 - Distribuição de tensões para a carga última nas vigas 1

e 2 do Ensaio 2 .

Figura 5.29 - Representação das fissuras na laje do Ensaio 2 130

Figura 5.30 - Detalhe da fissura que determinou o final do Ensaio 2 .... 130

Figura 5.31 - Detalhe das fissuras nas proximidades do pilar do

Ensaio 2

Figura 5.32 - Curva momento-rotação correspondente ao Ensaio 2...... 131

Figura 5.33 - Detalhe da cantoneira de alma durante o Ensaio 2......... 132

Figura 5.34 - Cantoneira de assento após o término do Ensaio 2......... 132

Figura 5.35 - Detalhe da rotação da ligação (Ensaio 2) ........................ 132

Figura 6.1 - Curva momento-rotação teórica, pelo método proposto por

Leon et al., 1996

Figura 6.2 - Representação das forças resistentes e do momento máximo da ligação

Figura 6.3 - Curva momento-rotação teórica, pela NBR 8800:2008....... 143

Figura 6.4 - Representação das forças resistentes na viga mista na região de momento negativo 
Figura 6.5 - Representação do modelo simplificado com o uso da ferramenta Ftool ................................................................. 145

Figura 7.1 - Comparação entre as curvas momento-rotação experimentais e a teórica ................................................... 146

Figura 7.2 - Aproximação da curva M- $\theta$ para o Ensaio 1 ..................... 147

Figura 7.3 - Aproximação da curva M- $\theta$ para o Ensaio 2 ..................... 147

Figura 7.4 - comparação entre as curvas $M-\theta$ aproximadas e as obtidas

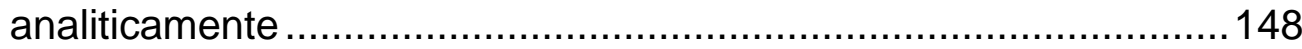

Figura 7.5 - Gráfico comparativo, entre os modelos experimentais e o modelo do Ftool, dos deslocamentos na viga ............................. 152

Figura 7.6 - Classificação da ligação segundo à rigidez e à resistência de acordo com o AISC ......................................................... 154

Figura 7.7 - Inspeção dos modelos experimentais: Pe01, Ensaio 1.......155 Figura 7.8 - Inspeção do modelos experimentais: região próxima ao Pe03, Ensaio 2 ......................................................................... 155

Figura 7.9 - Alongamento do furo na alma da Viga 2 e do furo na mesa da Viga 2, respectivamente - Ensaio 2.................................... 155 


\section{Lista de Tabelas}

Tabela 1.1- Estudos experimentais sobre conectores do tipo Perfobond

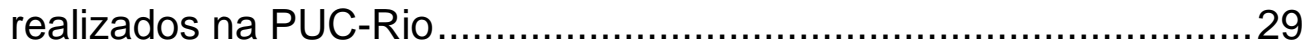

Tabela 1.2 - Estudos experimentais sobre ligações semirrígidas na PUC-Rio 30

Tabela 2.1 - Classificação das ligações segundo o AISC (adaptada de

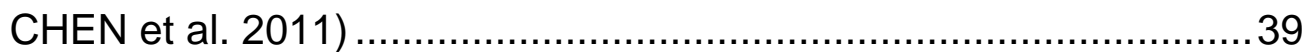

Tabela 2.2 - Classificação das ligações segundo o EC3...........................40

Tabela 2.3- Capacidade de rotação necessária $(\mathrm{mrad})-\beta_{\mathrm{vm}}=0,95 \ldots \ldots . .61$

Tabela 2.4 - Capacidade de rotação necessária (mrad) $-\beta_{v m}=0,90 \ldots .61$

Tabela 2.5 - Capacidade de rotação necessária $(\mathrm{mrad})-\beta v \mathrm{vm}=0,85 \ldots .61$

Tabela 3.1 - Estudo paramétrico: carga "q" encontrada através de uma distribuição de momentos fixa............................................................66

Tabela 3.2 - Características da Laje utilizada..........................................68

Tabela 3.3 - Cálculo do momento resistente variando-se o grau de

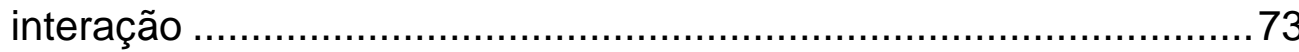

Tabela 3.4 - Valores dos momentos de inércia calculados .......................78

Tabela 4.1 - Perfis e tipos de aço utilizados nos ensaios ............................ 84

Tabela 4.2 - Dimensões medidas das cantoneiras de assento do ensaio 1 - valores médios .............................................................92

Tabela 4.3 - Dimensões medidas das cantoneiras de alma do ensaio 1 - valores médios

Tabela 4.4 - Dimensões medidas do pilar do ensaio 1 - valores médios .93

Tabela 4.5 - Dimensões medidas das vigas do ensaio 1 - valores médios 93

Tabela 4.6 - Dimensões medidas das cantoneiras de assento do ensaio 2 - valores médios

Tabela 4.7 - Dimensões medidas das cantoneiras de alma do ensaio 2 - valores médios

Tabela 4.8 - Dimensões medidas do pilar do ensaio 2 - valores médios .93

Tabela 4.9 - Dimensões medidas das vigas do ensaio 2 - valores médios. 
Tabela 4.10 - Resultados dos ensaios à compressão dos corpos de

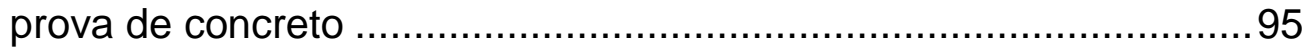

Tabela 4.11 - Propriedades mecânicas médias das barras de aço..........96

Tabela 4.12 - Estágios de carregamento do Ensaio 1 e principais

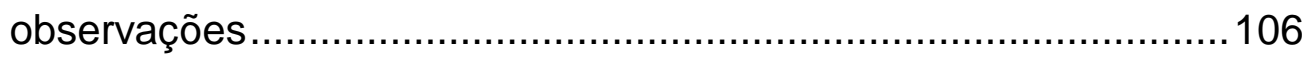

Tabela 6.1 - Valores correspondentes à curva M- $\theta$ da ligação estudada

Tabela 6.2 - Cálculo do momento fletor resistente de cálculo em regiões de momento negativo para o caso de estudo 144

Tabela 7.1 - Resumo dos resultados teóricos e experimentais para a ligação estudada.

Tabela 7.2 - Comparação dos momentos fletores máximos obtidos......149

Tabela 7.3 - comparação entre os momentos fletores resistentes para

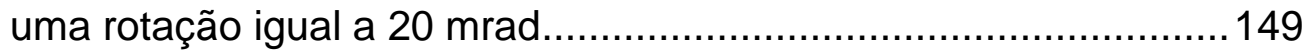

Tabela 7.4 - Comparação da rigidez de serviço .....................................150

Tabela 7.5 - Comparação da capacidade de rotação.............................. 151

Tabela 7.6 - Tabela comparativa entre os ensaios 1 e 2 ......................... 153 


\section{Lista de Símbolos}

\section{Letras Romanas}

$\mathrm{A}_{\mathrm{ac}} \quad$ área comprimida da seção do perfil de aço

$A_{\text {at }}$ área tracionada da seção do perfil de aço

$\mathrm{A}_{l} \quad$ área da cantoneira de assento

$A_{n L} \quad$ área líquida das cantoneiras de alma

$A_{s} \quad$ área de aço presente na largura efetiva da laje

$A_{w l} \quad$ área da dupla cantoneira de alma

$b_{c} \quad$ largura do pilar na direção transversal à viga

$b_{\text {ef }} \quad$ largura efetiva da laje de concreto

$\mathrm{Cr}$ força de compressão no perfil de aço

$\mathrm{Cr}^{\prime} \quad$ força de compressão na laje de concreto

$\mathrm{d}_{\mathrm{b}} \quad$ diâmetro dos parafusos

E módulo de elasticidade da viga de aço

$F_{b, R d} \quad$ resistência de cálculo de um parafuso

$f_{\text {ctm }}$

$f_{u 1}$

$f_{u 2}$

fc' resistência média do concreto à tração resistência à ruptura do aço estrutural da cantoneira resistência à ruptura do aço estrutural da mesa inferior do perfil de aço

$\mathrm{f}_{\mathrm{y}}$ resistência nominal ao escoamento do aço

$\mathrm{F}_{\mathrm{y}}$ tensão de escoamento do aço das cantoneiras

Fyrb tensão de escoamento do aço da armadura

$\mathrm{h}_{\mathrm{sc}} \quad$ altura do conector Perfobond

$\mathrm{I}_{\mathrm{b}} \quad$ momento de inércia da viga

$\mathrm{l}_{\mathrm{eq}} \quad$ momento de inércia equivalente da viga

I $\quad$ momento de inércia em regiões de momento positivo

ILB,PNA1 momento de inércia da viga mista para um grau de interação de 100\%

ILB,PNA7 momento de inércia da viga mista para um grau de interação de $25 \%$

$\mathrm{I}_{\mathrm{LB}, \mathrm{sS}} \quad$ momento de inércia para vigas biapoiadas

$\mathrm{I}_{\mathrm{LB}, \mathrm{ss}} \quad$ momento de inércia para vigas com ligação PR 
$\mathrm{I}_{\mathrm{n}} \quad$ momento de inércia em regiões de momento negativo

$\mathrm{K}_{\text {conn }} \quad$ rigidez da ligação

$\mathrm{K}_{\text {desc }} \quad$ rigidez de descarregamento da ligação

$\mathrm{Ki} \quad$ rigidez inicial da ligação

$\mathrm{K}_{\text {serv. }} \quad$ rigidez de serviço da ligação

$\mathrm{K}_{\tan } \quad$ rigidez tangente da ligação

$\mathrm{K}_{\tan } \quad$ rigidez tangente da ligação

$\mathrm{k}_{\mathrm{cs}} \quad$ rigidez inicial dos conectores de cisalhamento

$\mathrm{k}_{\mathrm{i}} \quad$ rigidez inicial da ligação inferior

$\mathrm{k}_{\mathrm{s}} \quad$ rigidez inicial das barras de aço

L $\quad$ comprimento da viga

$L_{b} \quad$ comprimento da viga

$\mathrm{M}_{\mathrm{a}} \quad$ momento fletor solicitante antes da cura do concreto

$M_{d} \quad$ momento fletor solicitante depois da cura do concreto

$M_{F} \quad$ momento fletor máximo para extremidade fixa

$\mathrm{M}_{\mathrm{n}, \mathrm{PNA1}}$ momento fletor resistente da viga mista para um grau de interação de 100\%

$\mathrm{M}_{\mathrm{n}, \mathrm{PNA}}$ momento fletor resistente da viga mista para um grau de interação de $25 \%$

$\mathrm{M}_{\mathrm{Rd}-} \quad$ momento fletor resistente da viga em regiões de momento negativo

$M_{n} \quad$ momento fletor resistente da viga mista

$\mathrm{M}_{\mathrm{n}, \mathrm{comp}} \quad$ momento fletor resistente da viga mista

M1 momento fletor da ligação para uma rotação igual a $2,5 \mathrm{mrad}$

$\mathrm{M}_{\mathrm{p}, \mathrm{viga}} \quad$ momento de plastificação da viga de aço

$M_{\text {ser }} \quad$ momento fletor da ligação para uma rotação igual a $2,5 \mathrm{mrad}$

$\mathrm{M}_{\text {serv }} \quad$ momento fletor na ligação para cargas de serviço

q carga distribuída

$q_{u} \quad$ resistência nominal ao cisalhamento do conector Perfobond

$\mathrm{S}^{(\mathrm{B})} \quad$ capacidade de deformação dos conectores de cisalhamento

$\mathrm{S}_{\mathrm{j}, \mathrm{ini}} \quad$ rigidez inicial da ligação

$t_{s c} \quad$ espessura do conector Perfobond

$Y_{\text {ENA }} \quad$ posição da linha neutra elástica

Y LNP posição da linha neutra plástica 
Y2 distância entre o topo do perfil de aço e o centroide do concreto em compressão

Y3 distância do topo do perfil de aço ao centroide do vergalhão

$Z_{x} \quad$ módulo de resistência plástico do perfil de aço

\section{Letras Gregas}

$\beta_{\mathrm{vm}} \quad$ coeficiente de redução do momento fletor resistente positivo da viga

$\delta_{\mathrm{fp}} \quad$ deslocamento para vigas com uma extremidade fixa e a outra apoiada

$\delta_{\mathrm{sr}} \quad$ deslocamento para vigas com ligações semirrígidas

$\Delta_{\text {ui }} \quad$ capacidade de deformação da ligação inferior

$\Delta_{\text {us }} \quad$ capacidade de deformação das barras de aço

$\varepsilon \quad$ deformação

deformação da armadura envolvida pelo concreto

deformação correspondente à resistência máxima à tração da armadura isolada

deformação correspondente à resistência de escoamento da armadura isolada rotação de serviço da ligação

$\theta_{\text {ser }}$ rotação da ligação para cargas de serviço

$\theta_{\text {serv }}$ grau de interação entre a laje e o perfil coeficiente de minoração da resistência 


\section{Lista de Abreviaturas}

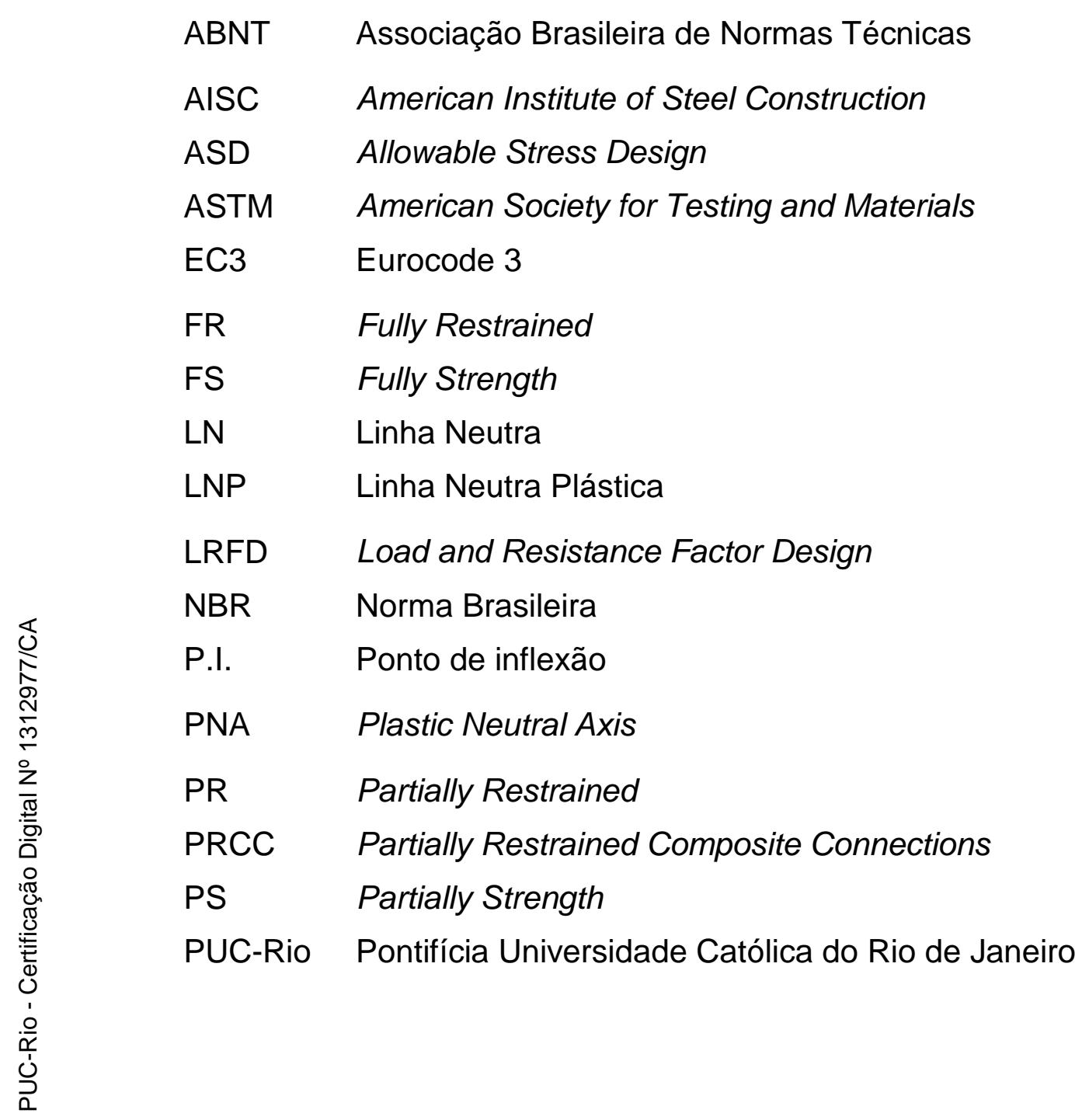

